\title{
No Difference in Reoperations at 2 Years Between Ceramic-on- metal and Metal-on-metal THA: A Randomized Trial
}

\author{
C. Anderson Engh Jr MD, Supatra Sritulanondha MPH, Abigail Korczak RN, \\ Terrence David Whalen BS, DC, Douglas D. R. Naudie MD, \\ Richard W. McCalden MD, Steven J. MacDonald MD
}

Published online: 2 July 2015

(C) The Association of Bone and Joint Surgeons $\mathbb{R} 2015$

\begin{abstract}
Background Hard-on-hard bearings for total hip arthroplasty continue to warrant analysis even though crosslinked polyethylene is performing very well. Ceramicon-metal (CoM) has low in vitro wear and did well in an early clinical trial. We report on a prospective, randomized, multicenter investigational device trial comparing $\mathrm{CoM}$ with metal-on-metal (MoM).

Questions/purposes (1) Is there a difference in the number or type of revisions comparing CoM with MoM? (2) Are cobalt and chromium metal levels different for CoM and MoM THA?

Methods Between August 2005 and October 2006, of 1015 patients screened, 390 patients were enrolled at 11 centers and randomized to $194 \mathrm{CoM}$ and $196 \mathrm{MoM}$
\end{abstract}

This research project was funded (CAE, SJM) through a research grant from DePuy, a Johnson \& Johnson Company (Warsaw, IN, USA). One of the authors certifies that he (CAE), or a member of his or her immediate family, has or may receive payments or benefits, during the study period, an amount more than USD 1,000,001, from DePuy (Warsaw, IN, USA). One of the authors certifies that he (SJM), or a member of his or her immediate family, has or may receive payments or benefits, during the study period, an amount of more than USD 1,000,001, from DePuy. One author (TDW) is an employee of DePuy. The institution of one or more authors (CAE, DDRN, RWM, SJM) has received funding from DePuy for the study. One or more authors (CAE, SJM) has received personal fees from DePuy outside the submitted work. One author (DDRN) has received institutional or personal fees from Smith \& Nephew (Memphis, TN, USA), Stryker (Warsaw, IN, USA), Pfizer (New York, NY, USA), Zimmer (Warsaw, IN, USA), and Exactech (Gainesville, FL, USA) outside the submitted work.

All ICMJE Conflict of Interest Forms for authors and Clinical Orthopaedics and Related Research ${ }^{\circledR}$ editors and board members are on file with the publication and can be viewed on request.

Clinical Orthopaedics and Related Research ${ }^{\circledR}$ neither advocates nor endorses the use of any treatment, drug, or device. Readers are bearings. There was no difference in the preoperative patient demographics between the study groups. Mean followup was 50 months (range, 22-75 months). Seventytwo patients from two centers had metal level analysis.

Results With the numbers available, there was no difference in the proportion of patients undergoing revisions between the MoM and the CoM cohorts (MOM: 3\% [six of 196]; COM: $1.5 \%$ [three of 194]; $\mathrm{p}=0.50$ ). Four MoM revisions were unrelated to the bearing surface. Two had bearing surface-related reoperations, one for an aseptic lymphocyte-dominated vasculitis-associated lesion and one for elevated metal levels with acetabular malposition. None of the CoM revisions were related to the bearing surface. The metal level analysis revealed that in contrast to the $\mathrm{CoM}$, the MoM bearing group had increasing values of

encouraged to always seek additional information, including FDAapproval status, of any drug or device prior to clinical use.

Each author certifies that his or her institution approved the human protocol for this investigation, that all investigations were conducted in conformity with ethical principles of research, and that informed consent for participation in the study was obtained.

This work was performed at Anderson Orthopaedic Research Institute, Alexandria, VA, USA, and London Health Sciences Centre-University Hospital, London, Ontario, Canada.

C. A. Engh Jr $(\bowtie)$, S. Sritulanondha

Anderson Orthopaedic Research Institute, 2501 Parker's Lane, Suite 200, Alexandria, VA 22306, USA

e-mail: andy@andersonclinic.com

A. Korczak, D. D. R. Naudie, R. W. McCalden, S. J. MacDonald Division of Orthopaedic Surgery, London Health Sciences Centre-University Hospital, London, ON, Canada

T. D. Whalen

DePuy Synthes, Warsaw, IN, USA 
erythrocyte and serum cobalt from 1 to 5 years (CoM erythrocyte $0.45-0.55 \mathrm{ppb}, \mathrm{p}=0.11$ and $\mathrm{CoM}$ serum $0.88-0.85, \mathrm{p}=0.55$, and MoM erythrocyte $0.32-0.51 \mathrm{ppb}$, $\mathrm{p}<0.01$ and MoM serum 0.65-1.01 ppb, p $<0.01$ ). In addition, the MoM cobalt levels in erythrocytes and serum at 5 years were more variable than at 1 year (erythrocyte interquartile range [IQR], $0.26-0.44$ to $0.31-1.21 \mathrm{ppb}$ and serum IQR, $0.42-0.80$ to $0.64-2.20 \mathrm{ppb}, \mathrm{p}<0.02$ for both). Conclusions Although both bearings performed well at short-term followup, the CoM bearing group had no wearrelated revisions and maintained consistently low metal levels. The MoM cobalt elevations may be important considering recent reports of taper corrosion. This CoM bearing was approved by the FDA but withdrawn from the market because of low sales. If it were available, the authors would not use CoM until long-term data were available. The bearing would have to outperform crosslinked polyethylene because it is unlikely that CoM metal levels will return to normal.

Level of Evidence Level I, therapeutic study.

\section{Introduction}

An ideal hip bearing surface would have qualities that include low wear with biologically friendly wear debris, allow larger head diameters, and be forgiving of component orientation. Crosslinked polyethylene is the current standard. However, head size is limited based on recommendations of minimum polyethylene thickness of 4 to $8 \mathrm{~mm}$. In addition, there is some concern about long-term in vivo oxidation with degraded wear performance in the second decade $[7,17]$. Ceramic-on-ceramic $(\mathrm{CoC})$ has the advantage of very low wear and comparatively friendly wear debris. However, ceramic head size is limited by the required liner thickness to avoid liner fracture. Most studies have reported instances of insertional liner fracture or squeaking, which also have limited CoC's popularity [9, 16]. Metal-on-metal (MoM) bearings became very popular because of the large head sizes available and the potential to greatly reduce dislocation. However, the debris generated has caused local tissue reactions in some patients leading to revision. For this reason large-head MoM bearing use is less common. A final concern associated with hip bearing surfaces is corrosion debris generated at the stem-ball taper. This debris has led to local tissue reactions requiring revision [6]. Although the evidence is limited, the taper junctions with corrosion and local tissue reactions appear to be more common when cobalt is present at the taper junction.

A ceramic-on-metal (CoM) bearing for THA has been studied in hip simulators and clinically at 12 months [1, 2, $4,5,8,10,11,19-23]$. The CoM bearing has potential advantages over other bearing surfaces. The metal insert can be thin allowing for $36-\mathrm{mm}$ heads in metal acetabular shells as small as $52 \mathrm{~mm}$. A final benefit of this bearing surface is the ceramic head interface with the femoral stem. Retrieval studies have demonstrated lower corrosion at the Morse taper when ceramic heads were used compared with metal heads [13]. The primary concern with a CoM bearing is the metal debris generated at the bearing surface and the potential biologic response. A prospective, multicenter, randomized clinical investigation comparing the $\mathrm{CoM}$ bearing surface with a MoM bearing was conducted under an FDA-approved Investigational Device Exemption (IDE). The results of this study have been submitted to the FDA but have not been published (FDA, 2009; DePuy Orthopaedics Inc IFU-78004780; DePuy Orthopaedics Inc SSED; DePuy Orthopaedics Inc 2006; DePuy Orthopaedics Inc PMA). This study reports the continued followup with a mean followup of 50 months (range, 22-75 months) for the 390 patients enrolled.

We asked the following questions: (1) Is there a difference in the number or type of revisions comparing CoM with MoM? (2) Are cobalt and chromium metal levels different for CoM and MoM THA?

\section{Patients and Methods}

We designed a multicenter prospective randomized blinded trial to compare CoM with MoM bearings using a variety of uncemented femoral stems and a titanium acetabular component. Between August 1, 2005, and October 31, 2006, 1015 patients from 11 centers were screened based on inclusion and exclusion criterion. Inclusion criteria included patients between the ages of 20 and 75 years with noninflammatory arthritis. Exclusion criteria included metal allergy, bilateral disease expected to require contralateral surgery in 2 years, and known cancer. Patients with a contralateral total hip were permitted as long as pain in that hip was mild or less. Three hundred ninety patients were enrolled. A block randomization with blocks of random size was provided by the sponsor. Investigators or designated research staff removed the next sequentially numbered sticker to reveal the treatment group. Subjects were blinded to their treatment.

All femoral and acetabular components were cementless. The same titanium acetabular shell and metal liner were used in all patients. The shell is porous-coated titanium with a $10^{\circ}$ self-locking taper for the metal bearing surface (Pinnacle; DePuy, J\&J, Warsaw, IN, USA). The inserted metal bearing surface is high carbon wrought cobalt chromium molybdenum alloy. Both $36-\mathrm{mm}$ and 28-mm inner diameters were used, although only 11 of 194 of the ceramic and 13 of 196 metal femoral heads were 
$28 \mathrm{~mm}$ in diameter. Twenty-eight-millimeter heads were used when the acetabular shell was smaller than $52 \mathrm{~mm}$ because a smaller size shell did not accommodate a $36-\mathrm{mm}$ head size. The MoM metal femoral heads were high carbon wrought cobalt chromium molybdenum alloy. The CoM ball was a Biolox Delta ceramic (CeramTec AG, Plochingen, Germany). Femoral stems were surgeonspecific (each surgeon used one type of stem) and subject to the randomization resulting in even distribution of stems. The femoral stems used at the sites included a cobaltchromium, extensively porous-coated, cylindrical (AML or Prodigy; DePuy, J\&J) in 94 hips (48 in the MoM group, 46 in the CoM group), a titanium proximally porous-coated dual taper (Summit; DePuy, J\&J) in 202 hips (101 in the MoM group, 101 in the CoM group), and a titanium proximally coated modular (SROM; DePuy, J\&J) in 94 hips (47 in the MoM group, 47 in the CoM group). The modular SROM stem has a 11/13 taper and all other stems are a 12/14 taper for the stem-ball junction. The surgical approach was also surgeon-specific; there were 265 lateral approaches (131 in the CoM group and 134 in the MoM group) and 125 posterior approaches (63 in the CoM group and 62 in the MoM group). There were no preoperative differences between the two groups in terms of age, sex, body mass index, diagnosis or Harris hip score (HHS) (Table 1).

A subset of the 390 patients included 72 consecutive patients from two centers who agreed to have metal level analysis. The centers were chosen because they had experience performing metal levels (Anderson Clinic and London Ontario, the senior author sites). The patients undergoing metal level analysis were a subset of the entire cohort. Screening and randomization were not different resulting in an equal number of patients in each study group (36 CoM and $36 \mathrm{MoM}$ ). The only difference in the patients undergoing metal level analysis was that one site used a cobalt chromium stem (AML or Prodigy) and the other site used a titanium stem (Summit). Blood samples were collected preoperatively and at 12-, 24-, and 60-month intervals after surgery for analysis of serum and erythrocyte cobalt and chromium metal levels. All collection tubes and containers were determined to be free of

Table 1. Demographics

\begin{tabular}{llll}
\hline Demographic & CoM & MoM & p value \\
\hline Age (years) & 59 & 60 & 0.984 \\
Gender (male) & $57 \%$ & $54 \%$ & 0.478 \\
BMI $\left(\mathrm{kg} / \mathrm{m}^{2}\right)$ & 30 & 30 & 0.972 \\
Diagnosis (OA) & $83 \%$ & $89 \%$ & 0.225 \\
Preoperative HHS (mean $\pm \mathrm{SD})$ & $48 \pm 12$ & $49 \pm 10$ & 0.851 \\
\hline
\end{tabular}

$\mathrm{CoM}=$ ceramic-on-metal; $\mathrm{MoM}=$ metal-on-metal $; \mathrm{BMI}=$ body mass index; $\mathrm{OA}=$ osteoarthritis; HHS = Harris hip score. trace metal, and care was taken to prevent metal contamination from the needle or collection tubes. Three 7-mL Sherwood Monoject tubes (Sherwood David and Geck, Markham, Ontario, Canada) of blood were drawn using 21gauge stainless steel needles. The first sample was discarded, the second vial was processed for red blood cell (RBC) evaluation, and the third vial processed for serum analysis. All blood samples were processed within 30 minutes and then transported to the Trace Element Laboratory at London Health Sciences Centre, London, Ontario, Canada. All serum and RBC samples were analyzed by high-resolution inductively coupled-mass spectrometry. The instrument detection limits are less than $1.0 \mathrm{ppb}$. Practical RBC detection limits are $0.05 \mathrm{ppb}$.

Clinical followup with HHS was done by the operating surgeon at each site at 4 weeks, 3 months, and annually. Radiographic evaluation was performed by a single reviewer for the same intervals excluding 3 months. Stable stems had less than $2 \mathrm{~mm}$ migration. Acetabular stability required less than $2 \mathrm{~mm}$ migration and less than $4^{\circ}$ change in inclination. Femoral or acetabular radiolucencies involving more than $50 \%$ of the implant surface were considered a sign of failure. Osteolytic lesions greater than $5 \mathrm{~mm}$ in the largest dimension were reported.

Ninety-five percent (369 of 390) of patients had minimum 2-year followup with a mean 50-month followup (Fig. 1). In the cohort of patients who had metal levels performed, $88 \%$ (63 of 72) had minimum 2-year metal levels and the mean followup is 52 months (Fig. 2). Two patients dropped out of the metal analysis group before 2 years because they had a contralateral MoM hip arthroplasty, which could have altered their levels after the index procedure but they were still followed in the larger clinical cohort.

The study was designed to show noninferiority (NI) of a success rate where success was defined as a composite of HHS, radiographic, and survivorship outcomes. An 8\% NI delta was used, and from previous IDE study G960262, the Ultima ${ }^{\circledR}$ MOM Total Hip System (DePuy, J\&J), success rates were anticipated to be $93 \%$ in both groups [12]. A power calculation indicated that sample sizes of 126 in each group would provide $80 \%$ power to demonstrate NI with a one-sided type 1 error rate of $5 \%$. Sample sizes were increased to 196 in each group to account for loss to followup. Although a composite of HHS, radiographic, and survivorship outcomes was chosen for the study design, the authors have chosen to present revision and metal level data as the primary manuscript questions. A KolgomorovSmirnov test was used to evaluate the normality of continuous data and Levene's test for homogeneity of variance was used to check for differences in variance. For nonparametric data, a Mann-Whitney U test was used to test for differences among two independent groups, a Wilcoxon 
Fig. 1 Clinical followup was obtained for $95 \%$ of the 390 subjects. Mean followup time was 50 months.

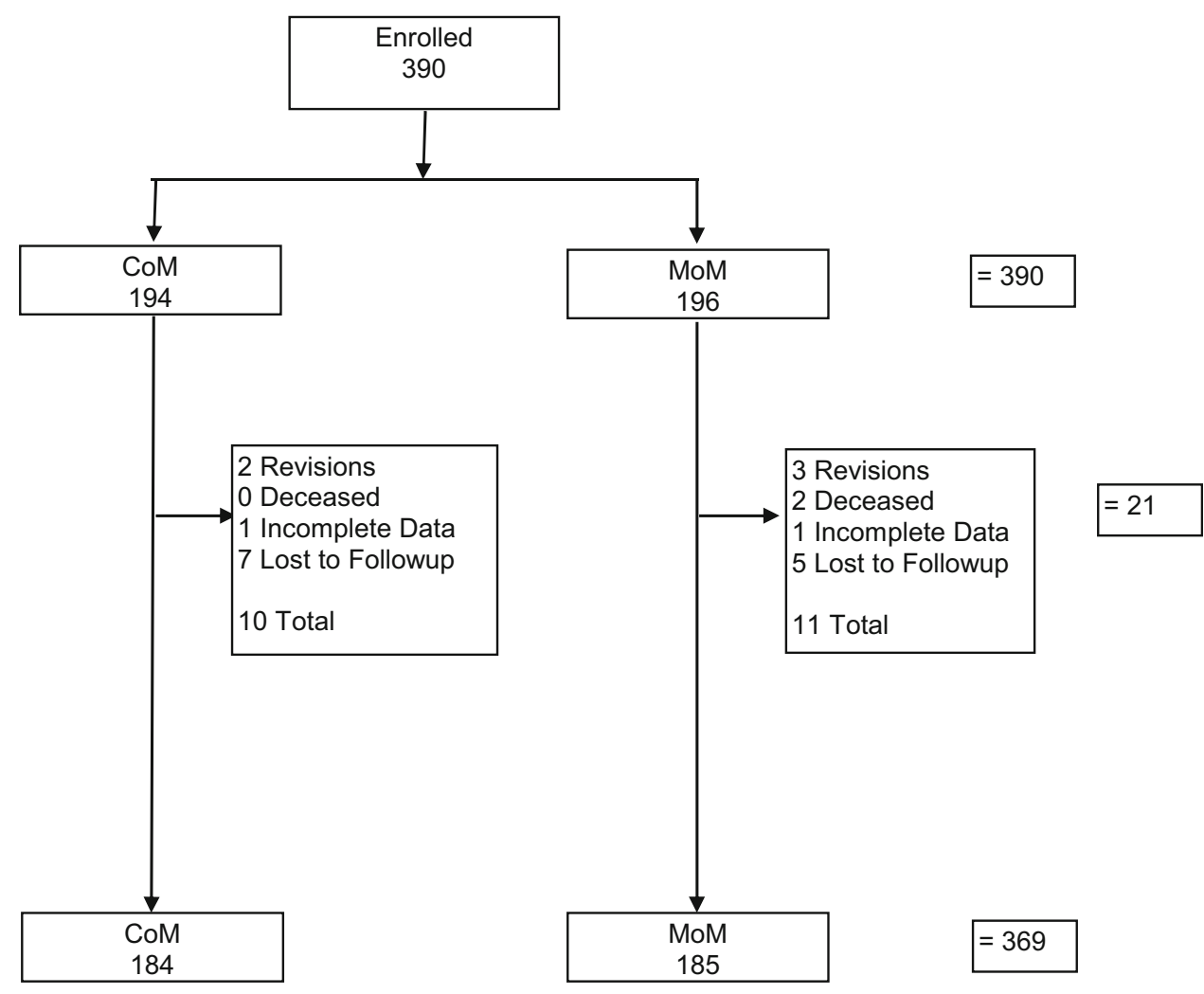

Followup at 2 Years or Greater Than 2 Years

$369 / 390=95 \%$

Mean Followup $=50$ Months

Range $=22-75$ Months signed-rank test was used for related variables, and Spearman's test was used to evaluate correlations. Fisher's exact test and the chi-square test were used to examine differences among categorical variables.

\section{Results}

There were six MoM revisions (six of 196 [3\%]) and three CoM revisions (three of 194 [1.5\%]) (odds ratio, 0.50; 95\% confidence interval [CI], 0.12-2.0; $\mathrm{p}=0.33$ ). The three CoM revisions included a hematoma evacuation at 2 weeks, an infection at 23 months, and excision of heterotopic ossification at 33 months. In the MoM group there were four revisions unrelated to the bearing surface and two bearing surface revisions. The four include a hematoma evacuation at 7 days, recurrent dislocation at 4 months, infection at 19 months, and a broken femoral component at 44 months. The first MoM revision attributed to the bearing surface was revised 44 months after surgery for an adverse local tissue reaction. This patient had pain and elevations of erythrocyte sedimentation rate and C-reactive protein. Preoperative hip aspiration revealed a culture-negative purulent material. The patient underwent a ball and liner exchange to a metal-on-polyethylene bearing surface. The second MoM revision attributed to the bearing surface occurred at 61 months. The patient developed hip squeaking associated with a serum chromium of $81 \mathrm{ppb}$ and serum cobalt of $204 \mathrm{ppb}$. The cup inclination was measured at $45^{\circ}$ to $48^{\circ}$. This patient also had a bearing exchange to a metal-on-polyethylene surface. The 5-year survivorships free of revision are 98\% (CI, 96\%-100\%) and $97 \%$ (CI, 94\%-100\%) for the CoM and MoM groups, respectively $(\mathrm{p}=0.30)$. We report implant radiographic data to address concerns about impending revisions. There are no hips with loose femoral or acetabular components and no acetabular osteolysis. Two patients in the MoM group and one patient in the CoM group have small femoral osteolytic lesions.

The metal level analysis revealed that CoM and MoM metal levels were not different at 5 years of followup ( $p$ values from 0.35 to 0.72 ) (Table 2 ). The only exception to 
Fig. 2 Cobalt and chromium ion levels were measured in a subset of 72 subjects at two sites.

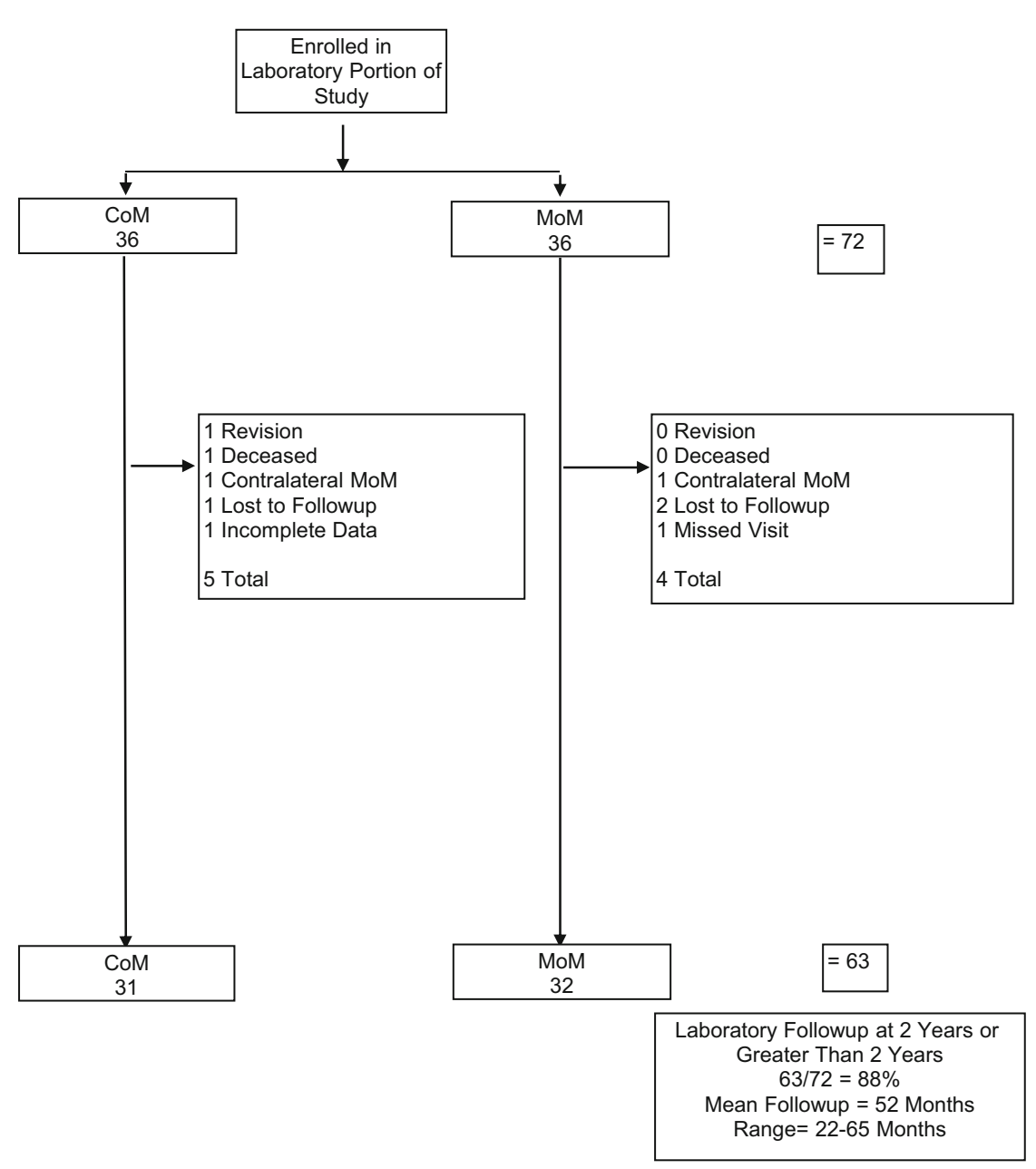

this was the 5-year erythrocyte chromium comparison in which the MoM level $(0.56 \mathrm{ppb}$; interquartile range [IQR], 0.34-0.99) was lower than the CoM (0.92 ppb; IQR, $0.77-1.36)(p=0.02)$. This isolated difference between the two groups at 5 years is not important because the CoM and MoM 5-year erythrocyte chromium levels were in the normal range and did not increase from the preoperative values (CoM 0.98 to $0.92 \mathrm{ppb}, \mathrm{p}=0.39$ and $\mathrm{MoM} 0.85$ to $0.56 \mathrm{ppb}, \mathrm{p}=0.17$ ) (Fig. 3). A difference existed analyzing the change within the CoM and MoM cobalt data from 1 to 5 years after surgery. The CoM erythrocyte and serum cobalt levels did not increase from 1 to 5 years (erythrocyte 0.45 to $0.55 \mathrm{ppb}, \mathrm{p}=0.11$ and serum 0.88 to $0.85, \mathrm{p}=$ $0.55)$. In contrast, the MoM erythrocyte and serum cobalt increased from 1 to 5 years (erythrocyte 0.32 to $0.51 \mathrm{ppb}, \mathrm{p}$ $<0.01$ and serum 0.65 to $1.01 \mathrm{ppb}, \mathrm{p}<0.01)$. The final difference between the CoM and MoM groups was seen comparing the cobalt data variability from 1 to 5 years. The CoM erythrocyte and serum cobalt metal level variability did not change (erythrocyte IQR, $0.28-0.83$ to $0.38-0.69$ $\mathrm{ppb}, \mathrm{p}=0.39$ and serum IQR, $0.54-1.49$ to $0.73-1.00 \mathrm{ppb}$, $\mathrm{p}=0.60$ ). In contrast, the MoM erythrocyte and serum cobalt values became more variable going from 1 to 5 years (erythrocyte IQR, 0.26-0.44 to $0.31-1.21 \mathrm{ppb}, \mathrm{p}=0.01$ and serum IQR, $0.42-0.80$ to $0.64-2.20 \mathrm{ppb}, \mathrm{p}<0.01$ ). The increasing MoM cobalt metal level variance can be seen visually as the increasing size of the MoM IQR (box plots) from 1 to 5 years (Fig. 4). There was no correlation between any metal level and cup inclination (CoM erythrocyte and serum cobalt $\mathrm{p}=0.84$ and 0.77 , CoM erythrocyte and serum chromium $\mathrm{p}=0.50$ and $0.54, \mathrm{MoM}$ erythrocyte and serum cobalt $\mathrm{p}=0.90$ and 0.53 , MoM erythrocyte and serum chromium $\mathrm{p}=0.34$ and 0.77 ). The mean cup inclination for the patients that had metal levels was $46^{\circ} \pm 8^{\circ}$ and $46^{\circ} \pm 8^{\circ}$ for the CoM and MoM groups, respectively $(\mathrm{p}=0.89)$.

\section{Discussion}

THA can be compromised by wear and the body's reaction to resulting debris. An ideal hip bearing surface would be characterized by low wear with biologically friendly wear debris, a variety of available head diameters, and tolerance 
Table 2. Cobalt and chromium ion concentration in erythrocytes and serum

\begin{tabular}{|c|c|c|c|c|c|c|c|}
\hline $\begin{array}{l}\text { Treatment } \\
\text { group }\end{array}$ & $\begin{array}{l}\text { Median } \\
\text { preoperative } \\
\text { concentration }\end{array}$ & $\begin{array}{l}\text { Median Year } 1 \\
\text { concentration }\end{array}$ & $\begin{array}{l}\text { Median Year } 5 \\
\text { concentration }\end{array}$ & $\begin{array}{l}\text { Intergroup } \\
\text { p value (COM, } \\
\text { MOM at Year 5) }\end{array}$ & $\begin{array}{l}\text { Intragroup } \\
\mathrm{p} \text { value } \\
\text { (preoperative and } \\
\text { Year 5) }\end{array}$ & $\begin{array}{l}\text { Intragroup } \\
\mathrm{p} \text { value (Year } 1 \\
\text { and Year 5) }\end{array}$ & $\begin{array}{l}\text { Intragroup variance } \\
\text { comparison (Year } 1 \\
\text { and Year 5) }\end{array}$ \\
\hline \multicolumn{8}{|c|}{ Erythrocyte cobalt } \\
\hline $\mathrm{CoM}$ & $0.08(0.07,0.13)$ & $0.45(0.28,0.83)$ & $0.55(0.38,0.69)$ & 0.72 & $<0.001$ & 0.11 & 0.39 \\
\hline MoM & $0.09(0.06,0.16)$ & $0.32(0.26,0.44)$ & $0.51(0.31,1.21)$ & & $<0.001$ & $<0.01$ & $<0.05$ \\
\hline \multicolumn{8}{|c|}{ Serum cobalt } \\
\hline $\mathrm{CoM}$ & $0.12(0.07,0.23)$ & $0.88(0.54,1.49)$ & $0.85(0.73,1.00)$ & 0.54 & $<0.001$ & 0.55 & 0.60 \\
\hline MoM & $0.12(0.09,0.16)$ & $0.65(0.42,0.80)$ & $1.01(0.64,2.20)$ & & $<0.001$ & $<0.01$ & $<0.01$ \\
\hline \multicolumn{8}{|c|}{ Erythrocyte chromium } \\
\hline $\mathrm{CoM}$ & $0.98(0.55,1.25)$ & $1.25(0.75,1.70)$ & $0.92(0.77,1.36)$ & $<0.05$ & 0.39 & 0.08 & 0.07 \\
\hline $\mathrm{MoM}$ & $0.85(0.43,1.25)$ & $1.43(0.75,2.60)$ & $0.56(0.34,0.99)$ & & 0.17 & $<0.01$ & $<0.01$ \\
\hline \multicolumn{8}{|c|}{ Serum chromium } \\
\hline $\mathrm{CoM}$ & $0.16(0.14,0.20)$ & $1.01(0.65,1.99)$ & $1.13(0.73,1.35)$ & 0.35 & $<0.001$ & 0.67 & 0.81 \\
\hline MoM & $0.14(0.11,0.22)$ & $0.84(0.61,1.24)$ & $0.95(0.60,1.41)$ & & $<0.001$ & 0.70 & 0.26 \\
\hline
\end{tabular}

Medians are reported with the interquartile range. The Mann-Whitney test was used to test for differences between groups. The Wilcoxon signedrank test was used for related variables. Levene's test for homogeneity of variance was used to check for differences in variance. The reference ranges for erythrocyte cobalt and serum cobalt are $0.02-0.29 \mathrm{ppb}$ and $0.03-0.40 \mathrm{ppb}$, respectively. The reference ranges for erythrocyte chromium and serum chromium are 0.04-0.64 ppb and 0.10-0.20 ppb, respectively; CoM = ceramic-on-metal; MoM = metal-on-metal.

Fig. 3 Looking at preoperative and 5-year levels, erythrocyte chromium in both the CoM and MoM groups showed no increase.

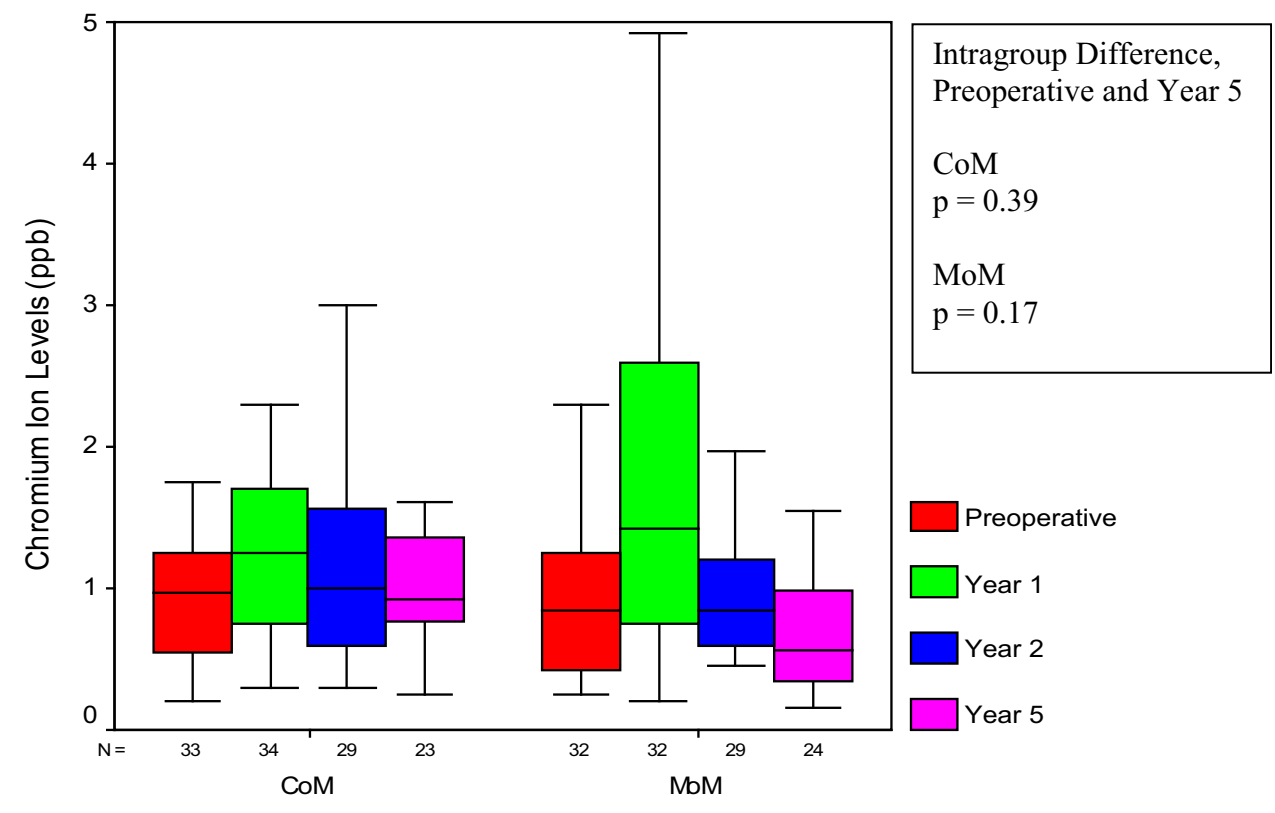

to variation in terms of component orientation. CoM bearings seem to offer some potential advantages. Hip simulator studies have demonstrated low wear comparable to $\mathrm{CoC}$ simulator wear, even in adverse conditions. The use of CoM would provide the advantages of low wear with the ability to use large femoral heads. CoM has been compared with MoM in two randomized trials but the followup was just 1 year [10, 20]. We therefore compared CoM with MoM bearings at mean 50-month (range, 22-75 months) followup in a prospective randomized multicenter study with the following questions: (1) Is there a difference in the number or type of revisions comparing CoM with MoM? (2) Are cobalt and chromium metal levels different for CoM and MoM THA?

A weakness of the study is the choice of MoM as the control bearing. In hindsight crosslinked polyethylene would have been a better control device. The study was designed and approved by the FDA before enrollment. 


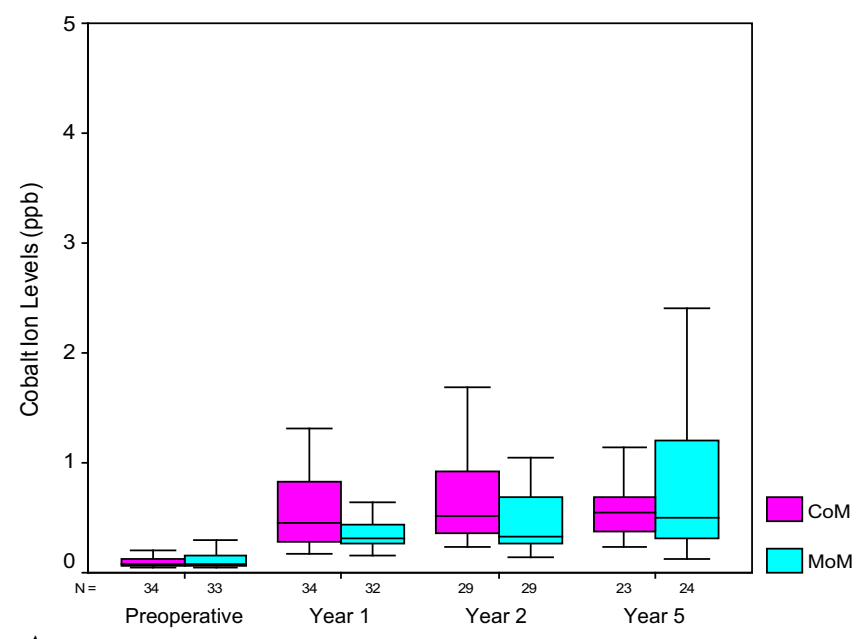

A

Fig. 4A-B For cobalt ions in the MoM group, the IQR increased over time in both erythrocytes (A) and serum (B).

Enrollment occurred from 2005 to 2006. During those years, MoM was a very popular bearing couple and 5-year data on crosslinked polyethylene were not yet available. Another weakness is the loss of 12 patients at the 2-year followup. Although this is less than $5 \%$ of the study population, it is possible that one or two additional revisions in these patients could influence the revision comparison of the two bearing surfaces. The use of more than one stem allowing for different material combinations and taper geometry is a concern. However, each surgeon used a single stem design and followed the randomization resulting in an equal number of a particular stem type in the two study groups. At the two centers that measured metal levels, the stems were different; however, comparisons of metal levels from the two sites were not different. Concerning metal levels, a reporting of acetabular anteversion would have been a good addition to the inclination data because increased wear from anterior or posterior edge loading associated with poor anteversion might influence metal levels. Lastly, we acknowledge that revision alone is a blunt measure of success.

In our comparison of MoM with CoM, revision rates were not different. There were six MoM revisions (3\% [six of 196]) compared with three CoM revisions (1.5\% [three of 194]). Although this seems like a small number of revisions, it is not much different from registry data. The 2014 Australian and UK Pinnacle MoM 3-year revision rates are $3 \%$ and $2.4 \%[3,18]$. The $2014 \mathrm{UK}$ also reports a $2.7 \%$ 3-year Pinnacle CoM revision rate. However, it is important to note that both the Australian and UK registries' 5-year Pinnacle MoM revision rates increase to $4.8 \%$ and $5 \%$, respectively. Currently MoM revisions for reasons related to adverse reactions to metal debris are not uncommon and modular, large-head MoM THAs have

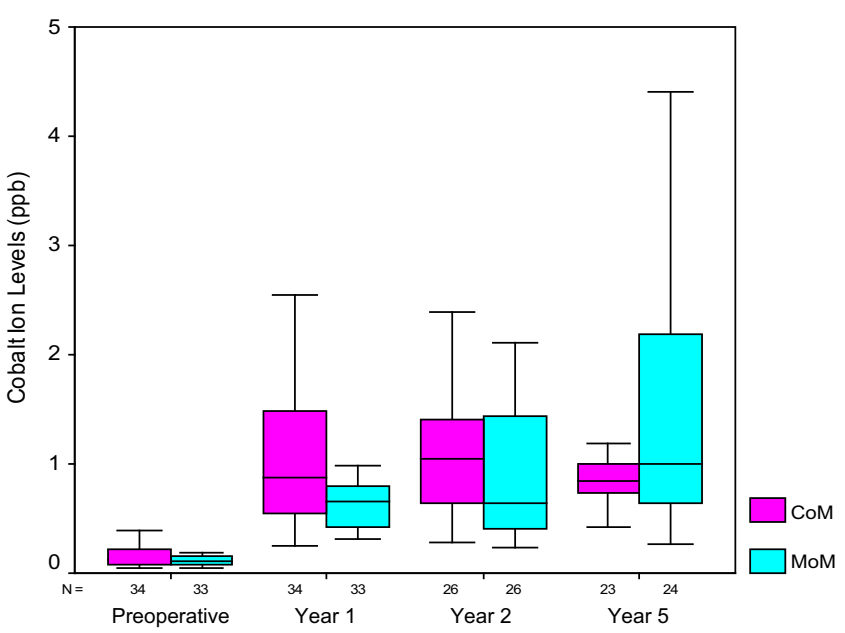

B

fallen into disuse. In this study there were two bearingrelated revisions in the MoM group and none in the CoM group. One patient with MoM presented with squeaking and very high metal levels, whereas the other had pain, culture-negative purulent-appearing joint fluid, and was revised for an adverse reaction to the MoM bearing. We are aware of two other studies comparing CoM with MoM [10, 20]. These studies focused on metal levels and only had 12-month followup. One of the studies reported CoM revisions unrelated to the bearing surface for infection and periprosthetic fracture [10]. With time we can expect more bearing-related revisions in the MoM group and will need to monitor the CoM bearings for the same type of failure. If existing simulator data are predictive of clinical function and patient outcome, the possibility exists that CoM bearings will have lower revision rates.

At 5 years the median cobalt and chromium levels were not different comparing the CoM with the MoM bearing. However, this does not mean there were no differences. The finding that MoM cobalt levels increased and became more variable over time may have implications for future MoM failures. This trend was not seen in the CoM group. Current research indicates that MoM failures can occur with or without bearing surface wear and that trunnion corrosion is a cause of failure in some hips [14, 15]. This is interesting in light of our metal level trends. Bearing surface failures in patients may be associated with the comparatively higher simulator wear for MoM compared with CoM. In addition, increased metal debris can originate at the ball-stem taper junction secondary to corrosion. One clinical study of metal-on-polyethylene failure has identified a tendency for cobalt levels to increase preferentially to chromium levels when corrosion is a cause of failure [6]. Another study has demonstrated that corrosion is lower 
with a ceramic to metal taper junction than a metal to metal taper junction [13]. We speculate that lower bearing surface wear and less corrosion may contribute to the stable and comparatively low variability of the CoM cobalt levels. We are aware of two studies that compared CoM with MoM metal levels. One study reported lower 12month CoM chromium but not cobalt levels compared with MoM [10]. The other study found no difference comparing CoM with MoM metal levels at 6 or 12 months [20]. Neither of these studies had long enough followup to recognize the 2- to 5-year MoM and CoM trends that we report. Still it is important to remember that postoperative CoM metal levels were elevated compared with the preoperative state. The finding that both CoM and MoM erythrocyte chromium remained at normal levels is important, because it implies that the more toxic hexavalent chromium is not being absorbed.

At a mean followup of 50 months, there was no difference comparing the MoM with CoM revision rate or the comparison of MoM with CoM median metal levels in the subset that had metal levels performed. However, the bearing related revisions and increasing cobalt levels for the MoM group will likely contribute to higher future MoM revisions. It remains to be answered if the elevated but stable CoM metal levels will continue and if revisions related to the bearing surface will also remain low. Assuming good future CoM performance, the bearing will have to be compared with crosslinked polyethylene, which is the most common bearing surface today. The CoM bearing described in this study was approved by the FDA but withdrawn from the market because of low sales. If it were available, the authors would not use CoM until long-term data were available. The bearing would have to outperform crosslinked polyethylene because it is unlikely that CoM metal levels will return to normal.

Acknowledgments We thank Robert Schneider MD, who performed the radiographic review for the study.

\section{References}

1. Affatato S, Spinelli M, Squarzoni S, Traina F, Toni A. Mixing and matching in ceramic-on-metal hip arthroplasty: an in-vitro hip simulator study. J Biomech. 2009;42:2439-2446.

2. Affatato S, Spinelli M, Zavalloni M, Traina F, Carmignato S, Toni A. Ceramic-on-metal for total hip replacement: mixing and matching can lead to high wear. Artif Organs. 2010;34:319-323.

3. Australian Orthopaedic Association National Joint Replacement Registry. Metal on Metal Bearing Surface Total Conventional Hip Arthroplasty Supplementary Report 2014. Available at: https://aoanjrr.dmac.adelaide.edu.au/documents/10180/172288/ Metal\%20on\%20Metal\%20Total\%20Conventional\%20Hip\%20 Arthroplasty. Accessed May 13, 2015.
4. Barnes CL, DeBoer D, Corpe RS, Nambu S, Carroll M, Timmerman I. Wear performance of large-diameter differentialhardness hip bearings. J Arthroplasty. 2008;23(Suppl 1):56-60.

5. Cigada A, Cotogno G, Chiesa R. The ceramic-on-metal coupling in total hip replacements for young patients: a review study. J Appl Biomater Biomech. 2011;9:2-10.

6. Cooper HJ, Della Valle CJ, Berger RA, Tetreault M, Paprosky WG, Sporer SM, Jacobs JJ. Corrosion at the head-neck taper as a cause for adverse local tissue reactions after total hip arthroplasty. J Bone Joint Surg Am. 2012;94:1655-1661.

7. Currier BH, Van Citters DW, Currier JH, Collier JP. In vivo oxidation in remelted highly cross-linked retrievals. $J$ Bone Joint Surg Am. 2010;92:2409-2418.

8. Firkins PJ, Tipper JL, Ingham E, Stone MH, Farrar R, Fisher J. A novel low wearing differential hardness, ceramic-on-metal hip joint prosthesis. J Biomech. 2001;34:1291-1298.

9. Hamilton WG, McAuley JP, Dennis DA, Murphy JA, Blumenfeld TJ, Politi J. THA with Delta ceramic on ceramic: results of a multicenter investigational device exemption trial. Clin Orthop Relat Res. 2010;468:358-366.

10. Isaac GH, Brockett C, Breckon A, van der Jagt D, Williams S, Hardaker C, Fisher J, Schepers A. Ceramic-on-metal bearings in total hip replacement. J Bone Joint Surg Br. 2009;91:1134-1141.

11. Ishida T, Clarke IC, Donaldson TK, Shirasu H, Shishido T, Yamamoto K. Comparing ceramic-metal to metal-metal total hip replacements-a simulator study of metal wear and ion release in 32- and 38-mm bearings. J Biomed Mater Res B Appl Biomater. 2009;91:887-896.

12. Jacobs M, Gorab R, Mattingly D, Trick L, Southworth C. Threeto six-year results with the Ultima metal-on-metal hip articulation for primary total hip arthroplasty. J Arthroplasty. 2004;19:48-53.

13. Kurtz SM, Kocagöz SB, Hanzlik JA, Underwood RJ, Gilbert JL, MacDonald DW, Lee GC, Mont MA, Kraay MJ, Klein GR, Parvizi J, Rimnac CM. Do ceramic femoral heads reduce taper fretting corrosion in hip arthroplasty? A retrieval study. Clin Orthop Relat Res. 2013;471:3270-3282.

14. Langton DJ, Jameson SS, Joyce TJ, Gandhi JN, Sidaginamale R, Mereddy P, Lord J, Nargol AVF. Accelerating failure rate of the ASR total hip replacement. J Bone Joint Surg Br. 2011; 93:1011-1016.

15. Langton DJ, Sidaginamale R, Lord JK, Nargol AV, Joyce TJ. Taper junction failure in large-diameter metal-on-metal bearings. Bone Joint Res. 2012;1:56-63.

16. Mesko JW, D'Antonio JA, Capello WN, Bierbaum BE, Naughton M. Ceramic-on-ceramic hip outcome at a 5- to 10-year interval: has it lived up to its expectations? J Arthroplasty. 2011;26:172-177.

17. Muratoglu OK, Wannomae KK, Rowell SL, Micheli BR, Malchau H. Ex vivo stability loss of irradiated and melted ultra-high molecular weight polyethylene. J Bone Joint Surg Am. 2010; 92:2809-2816.

18. National Joint Registry for England, Wales and Northern Ireland 11th Annual Report 2014. Available at: http://www.njrcentre.org. uk/njrcentre/Portals/0/Documents/England/Reports/11th_annual_ report/NJR\%2011th\%20Annual\%20Report\%202014.pdf. Accessed May 13, 2015

19. Reinders J, Sonntag R, Heisel C, Reiner T, Vot L, Kretzer JP. Wear performance of ceramic-on-metal hip bearings. PLoS One. 2013;8:e73252.

20. Schouten R, Malone AA, Tiffen C, Frampton CM, Hooper G. A prospective, randomised controlled trial comparing ceramic-onmetal and metal-on-metal bearing surfaces in total hip replacement. J Bone Joint Surg Br. 2012;94:1462-1467.

21. Williams S, Al-Hajjar M, Isaac GH, Fisher J. Comparison of ceramic-on-metal and metal-on-metal hip prostheses under adverse conditions. J Biomed Mater Res B Appl Biomater. 2013;101:770-775. 
22. Williams S, Schepers A, Isaac G, Hardaker C, Ingham E, van der Jagt D, Breckon A, Fisher J. The 2007 Otto Aufranc Award. Ceramic-on-metal hip arthroplasties: a comparative in vitro and in vivo study. Clin Orthop Relat Res. 2007;465:23-32.
23. Williams SR, Wu JJ, Unsworth A, Khan I. Wear and surface analysis of $38 \mathrm{~mm}$ ceramic-on-metal total hip replacements under standard and severe wear testing conditions. Proc Inst Mech Eng H. 2011;225:783-796. 